\title{
Accuracy of genomic predictions in Gyr (Bos indicus) dairy cattle
}

\author{
S. A. Boison, ${ }^{*}$ A. T. H. Utsunomiya,† D. J. A. Santos,† H. H. R. Neves,†‡ R. Carvalheiro,† G. Mészáros, ${ }^{*}$ \\ Y. T. Utsunomiya,† A. S. do Carmo,§ R. S. Verneque,§ M. A. Machado,§ J. C. C. Panetto,§ J. F. Garcia,\# \\ J. Sölkner, ${ }^{*}$ and M. V. G. B. da Silva ${ }^{1}$ \\ *Department of Sustainable Agricultural Systems, University of Natural Resources and Life Sciences, 1180, Vienna, Austria \\ †Faculdade de Ciências Agrárias e Veterinárias, Universidade Estadual Paulista (UNESP), Jaboticabal, SP, 14884-900, Brazil \\ $\ddagger$ GenSys Consultores Associados S/C Ltda, Porto Alegre 90680-000, Brazil \\ §Empresa Brasileira de Pesquisa Agropecuária, Embrapa Gado de Leite, Juiz de Fora, MG, 360381330, Brazil \\ \#Faculdade de Medicina Veterinária de Araçatuba, Universidade Estadual Paulista (UNESP), Araçatuba, SP, 16015-050, Brazil
}

\begin{abstract}
Genomic selection may accelerate genetic progress in breeding programs of indicine breeds when compared with traditional selection methods. We present results of genomic predictions in Gyr (Bos indicus) dairy cattle of Brazil for milk yield (MY), fat yield (FY), protein yield (PY), and age at first calving using information from bulls and cows. Four different single nucleotide polymorphism (SNP) chips were studied. Additionally, the effect of the use of imputed data on genomic prediction accuracy was studied. A total of 474 bulls and 1,688 cows were genotyped with the Illumina BovineHD (HD; San Diego, CA) and BovineSNP50 (50K) chip, respectively. Genotypes of cows were imputed to HD using FImpute v2.2. After quality check of data, 496,606 markers remained. The HD markers present on the GeneSeek SGGP-20Ki (15,727; Lincoln, NE), 50K $(22,152)$, and GeneSeek GGP-75Ki $(65,018)$ were subset and used to assess the effect of lower SNP density on accuracy of prediction. Deregressed breeding values were used as pseudophenotypes for model training. Data were split into reference and validation to mimic a forward prediction scheme. The reference population consisted of animals whose birth year was $\leq 2004$ and consisted of either only bulls (TR1) or a combination of bulls and dams (TR2), whereas the validation set consisted of younger bulls (born after 2004). Genomic BLUP was used to estimate genomic breeding values (GEBV) and reliability of GEBV $\left(\mathrm{R}_{\mathrm{PEV}}^{2}\right)$ was based on the prediction error variance approach. Reliability of GEBV ranged from $\sim 0.46$ (FY and PY) to 0.56 (MY) with TR1 and from 0.51 (PY) to 0.65 (MY) with TR2. When averaged across all traits, $R_{P E V}^{2}$ were substan-
\end{abstract}

Received August 1, 2016.

Accepted January 3, 2017.

${ }^{1}$ Corresponding author: marcos.vb.silva@embrapa.br tially higher $\left(\mathrm{R}_{\mathrm{PEV}}^{2}\right.$ of $\mathrm{TR} 1=0.50$ and $\left.\mathrm{TR} 2=0.57\right)$ compared with reliabilities of parent averages (0.35) computed from pedigree data and based on diagonals of the coefficient matrix (prediction error variance approach). Reliability was similar for all the 4 marker panels using either TR1 or TR2, except that imputed HD cow data set led to an inflation of reliability. Reliability of GEBV could be increased by enlarging the limited bull reference population with cow information. A reduced panel of $\sim 15 \mathrm{~K}$ markers resulted in reliabilities similar to using HD markers. Reliability of GEBV could be increased by enlarging the limited bull reference population with cow information.

Key words: indicine, genomic selection, small population, genotyping females

\section{INTRODUCTION}

The past decade has seen increasing adoption of genomic evaluations (termed as genomic selection; GS) in taurine dairy cattle populations around the world. The benefit of using whole-genome dense marker panel information for estimating genomic breeding values (GEBV) has been seen for several plant and animal populations. In dairy cattle populations, genomic evaluation has caused an increase in genetic gain (Hutchison et al., 2014) and accuracy of selection (VanRaden et al., 2009; Su et al., 2010) and a drastic decrease in generation interval (Schaeffer, 2006; Hutchison et al., 2014) compared with traditional selection methods. Genomic breeding values are estimated for genotyped individuals using estimate of marker effects (Meuwissen et al., 2001; Habier et al., 2011; Erbe et al., 2012). Alternatively, genomic relationships obtained from dense genome-wide SNP markers or a combination of marker genotypes and pedigree information are also widely used (VanRaden, 2008; Legarra et al., 2009).

In most dairy cattle populations, the reference population for genomic selection are mainly made up 
Table 1. Total number of animals with phenotypes and genotypes for milk (MY), protein (PY), and fat (FY) yield and age at first calving $(\mathrm{AFC})$

\begin{tabular}{lccc}
\hline Trait & $\begin{array}{c}\text { Total } \\
\text { number } \\
\text { of animals }\end{array}$ & $\begin{array}{c}\text { Number } \\
\text { of bulls }\end{array}$ & $\begin{array}{c}\text { Number } \\
\text { of cows }\end{array}$ \\
\hline MY & 2,023 & 433 & 1,590 \\
FY & 1,871 & 400 & 1,471 \\
PY & 1,556 & 379 & 1,177 \\
AFC & 2,004 & 422 & 1,582 \\
\hline
\end{tabular}

of progeny-tested bulls with reliable pseudophenotypes [mostly, deregressed breeding values (dEBV) or daughter yield deviations]. However, in populations with a limited number of progeny-tested bulls, several other alternatives have been suggested. Some of the adopted approaches include sharing genotypes within and across countries by several breeding organizations such as Interbull (http://www.interbull.org/ib/ interbullcentremain; Wiggans et al., 2015), combining information across breeds (Hayes et al., 2009; Hozé et al., 2014), and adding genotyped cows to the reference populations (Wiggans et al., 2011; Ding et al., 2013; Thomasen et al., 2014; Lourenco et al., 2014). Addition of cows to reference populations is an attractive alternative, as cow information is more readily available; however, GEBV have been reported to be biased when elite cows are added to reference population in genomic evaluations (Dassonneville et al., 2012).

Genomic selection has been well studied in both large and small populations of Bos taurus dairy cattle breeds (VanRaden et al., 2009; Luan et al., 2009; Mulder et al., 2010; Brøndum et al., 2011). However, a dearth of knowledge exists on the potential of GS in Bos indicus dairy cattle populations. Recent studies in an indicine beef cattle population (Nelore) suggested that GS is a feasible alternative to traditional selection approaches (Neves et al., 2014). The present study was undertaken on Gyr (Bos indicus), which is an important dairy cattle breed of Brazil. The Brazilian Gyr cattle have gained prominence as an efficient milk production breed in the tropics, producing relatively high amount of milk $(\sim 3,000 \mathrm{~kg}$ of milk per $305 \mathrm{DIM})$ and having good adaptability to tropical conditions, such as resistance to ticks, worms, and mastitis (Santana et al., 2014). In Brazil, about $80 \%$ of dairy herds are composed of Gyr and their crosses with Holstein. The Gyr breed is known to have about 400,000 registered animals in its national herdbook; however, progeny testing of bulls began only about 3 decades ago and the number of bulls that have been involved in the program is about 450 (Santana et al., 2014). Furthermore, DNA samples from some progeny-tested bulls and most of the nonprogeny-tested bulls from the Brazilian population were not stored. Thus, in Gyr, a large reference population for preliminary GS study required the addition of cow data to the limited bull data set. The overall aim of the current study was to test the feasibility of genomic selection in Brazilian Gyr on milk production traits and age at first calving.

\section{MATERIALS AND METHODS}

\section{Phenotype Data}

Pseudophenotypes used as response variables in genomic models were dEBV for milk yield (MY), fat yield (FY), protein yield (PY), and age at first calving (AFC), computed for both bulls and cows of Brazilian Gyr dairy cattle. Deregression of EBV followed the procedure of Garrick et al. (2009). The EBV were obtained from the 2014 routine genetic evaluation with 28,133 individuals of Embrapa Gado de Leite, Juiz de Fora, Brazil. For genomic prediction analysis, individuals (bulls and cows) with EBV reliability $<0.25$ were discarded. Heritability estimates were 0.28 for MY, 0.22 for both FY and PY, and 0.18 for AFC. Table 1 shows the number of animals used for genomic prediction after quality check of both phenotype and genotype data set. The distribution of sires and dams across birth years is presented in Figure 1.

\section{Genotype Data}

Four hundred seventy-four bulls and 1,688 cows were genotyped with the Illumina BovineHD (HD; Illumina, San Diego, CA) and Illumina BovineSNP50 (50K) BeadChip, respectively. Quality check (QC) was performed using PLINK v1.07 (Purcell et al., 2007). Samples with a call rate $<90 \%$ were removed from the analysis. Nonautosomal and unmapped SNP were discarded. Markers deviating from Hardy-Weinberg equilibrium (Fisher's exact test; $P$-value $<10^{-6}$ ) and those with call rate $<90 \%$ were also removed. In addition to the above QC, markers with minor allele frequency $<2 \%$ were deleted for Illumina HD. Mendelian inconsistencies were checked and pedigree relationships as well as discordant markers were set to unknown and missing. After QC, 471 bulls with 496,606 SNP and 1,644 cows with 47,668 SNP remained. Out of the 47,668 markers, 22,152 were present on the quality checked Illumina HD.

To be able to undertake genomic prediction with the HD markers using data from bulls and cows, the latter were imputed from Illumina $50 \mathrm{~K}$ to HD with FImpute version 2.2 (Sargolzaei et al., 2014). Genotyped bulls were used to generate the haplotype library needed for the imputation of cows genotypes to Illumina HD. Ad- 
ditional details about the imputation process can be obtained from Boison et al. (2015).

\section{Genotyping Strategies}

Lower-Density SNP Panel. The SNP list from 3 different chips were used to study the impact of using lower-density panel (LDP) instead of using highdensity panel (HDP) for genomic evaluations. This strategy aims to study the effect of minimizing cost of genomic evaluations by using LDP. Three commercially available SNP chips were studied: Illumina 50K,
GeneSeek super genomic profiler (SGGP-20Ki; Geneseek, Lincoln, NE), and GeneSeek genomic profiler (GGP-75Ki). Markers that were common between Illumina HD (after QC) and the LDP were subset and used. Genomic predictions were then undertaken using genotyped data of bulls and cows from HD $(496,606$ SNP), GGP-75Ki (65,018 SNP), 50K (22,152 SNP), and SGGP-20Ki (15,727 SNP).

Imputation of Selection Candidates. To reduce the cost of implementing genomic evaluation in breeding programs, selection candidates can be genotyped with an LDP and imputed to a preferred HDP. We mimicked
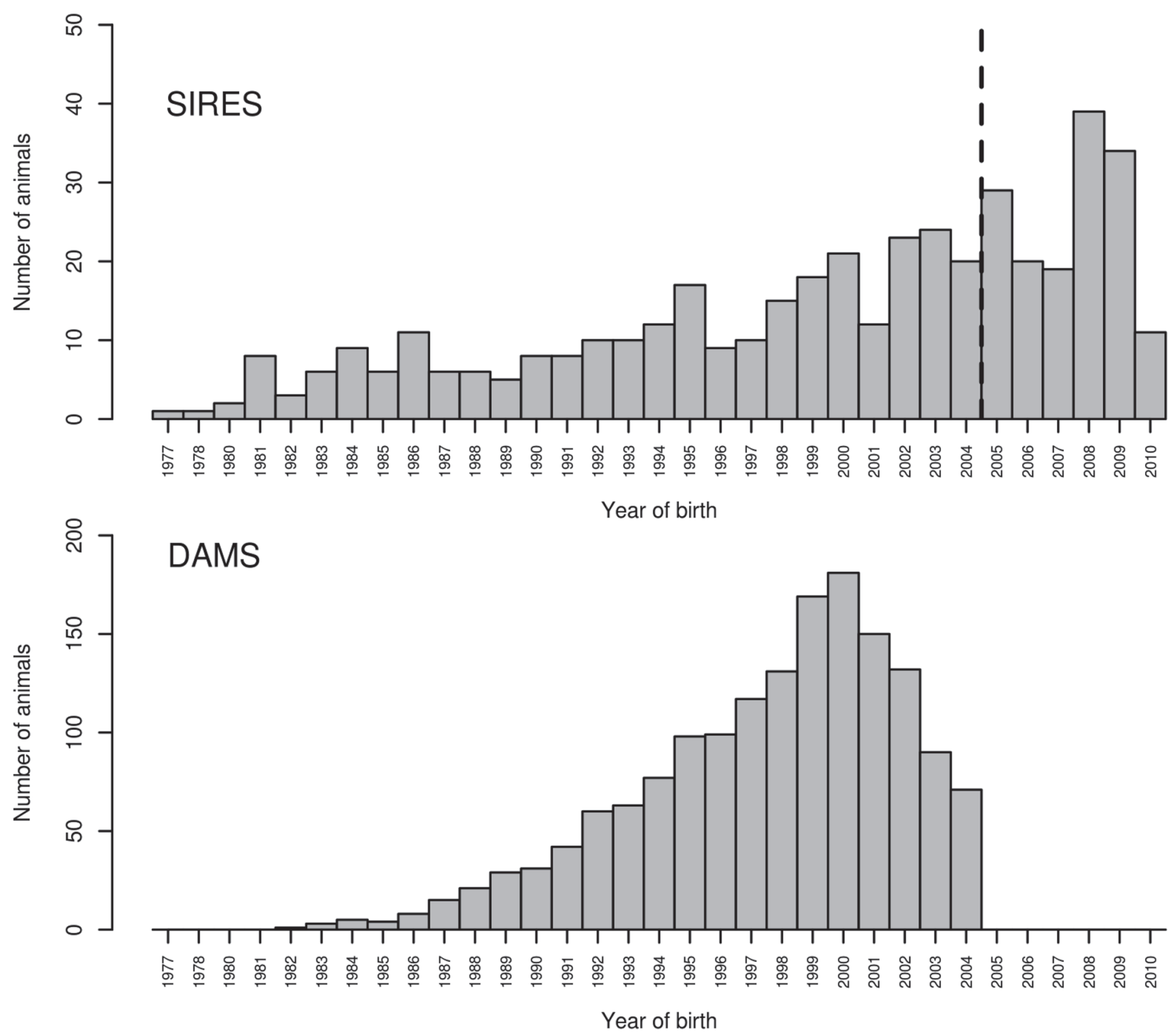

Figure 1. Distribution of bulls and cows across birth years. Animals born after the year 2004 were used as validation animals (dotted line). 
this approach by imputing selection candidates from the 3 LDP (50K, SGGP-20Ki, and GGP-75Ki) to HDP (HD). Imputation accuracy was computed as the correlation of true and imputed genotypes and as allelic correct rate (Boison et al., 2015).

\section{Statistical Methods}

Genomic breeding values were estimated using genomic BLUP (GBLUP) as implemented in GEBV software (Sargolzaei et al., 2011), which estimated genomic breeding values by solving the following mixed model equation:

$$
\mathbf{y}=1 \mu+\mathrm{Zg}+\mathbf{e}
$$

where $\mathbf{y}$ is a vector of phenotypes (dEBV), $\mathbf{1}$ is a vector of ones representing the overall mean $(\mu), \mathbf{Z}$ is the incidence matrix relating GEBV to $\mathbf{y}, \mathbf{g}$ is the vector of GEBV, and $\mathbf{e}$ is the vector of random residual terms. It was assumed that $\mathbf{g} \sim N\left(0, \mathbf{G} \sigma_{\mathbf{g}}^{2}\right)$ and $\mathbf{e} \sim N\left(0, \mathbf{D} \sigma_{\mathbf{e}}^{2}\right)$. $\mathbf{G}$ is the genomic relationship matrix following (VanRaden, 2008):

$$
\mathbf{G}=T T^{\prime}\left[2 \sum_{i=1}^{l} p_{i}\left(1-p_{i}\right)\right]^{-1}
$$

where $T=\mathbf{M}-\mathbf{P} ; \mathbf{M}$ is a matrix of genotypes coded as $(0,1,2)$ with $N$ number of genotyped animals by $l$ number of markers; $\mathbf{P}$ is a matrix defined aiming to set mean values of the allele effects to 0 , so that elements in its $i$ th column equals $2 p_{i}$, where $p_{i}$ is the allelic frequency for marker $i$. Allele frequencies were estimated from the observed genotype data; $\sigma_{\mathbf{g}}^{2}$ and $\sigma_{\mathbf{e}}^{2}$ are the genetic and residual variances; and $\mathbf{D}$ was a diagonal matrix with weights $w^{-1}$. For animal $j$,

$$
w_{j}=\frac{1-h^{2}}{\left[c+\left(1-r_{j}^{2}\right) / r_{j}^{2}\right] h^{2}},
$$

$c$ was set to 0 , which implies an assumption that markers account for all additive variance, $r_{j}^{2}$ is the reliability of dEBV for animal $j$, and $h^{2}$ is the heritability of the trait. Genomic breeding values $(\hat{g})$ of GBLUP were thus computed as

$$
\hat{g}=\mathbf{G}\left[\mathbf{G}+\mathbf{D}\left(\frac{\sigma_{\mathbf{e}}^{2}}{\sigma_{\mathbf{g}}^{2}}\right)\right]^{-1}(y-1 \mu) .
$$

\section{Validation Schemes}

The forward prediction scheme was used to assess the potential of using genomic predictions in Gyr. Validation animals were young bulls born after year 2004, whereas the reference animals were either bulls (TR1) or a combination of bulls and cows (TR2) born before the year 2004 (included). Descriptive statistics of the EBV and their reliability or the reference and validation animals are presented in Table 2. Estimated breeding values for the reference and validation animals were computed at 2014. Designing a forward prediction scheme this way leads to inflated accuracies, as EBV of reference animals will contain information from validation animals (Amer and Banos, 2010; Olson et al., 2011). However, the structure of the Gyr breeding program is such that truncating the phenotypic records (at year 2004) for the estimation of breeding values for the reference animals $(\mathrm{n}=\sim 273)$ will effectively mean that only about $\sim 180$ sires will have reliable dEBV. This is because, a small number of daughters (20-30 daughters per sire) provide information to the progenytesting scheme.

About 94 (TR1) and 100\% (TR2) of the validation animals had at least 1 parent in the reference population. Another important statistic that helps to contextualize our results is the relatedness between reference and validation animals (Daetwyler et al., 2013). Relatedness between reference and validation animals were computed based on the genomic relationship matrix (G) as $S^{-1}\left[\sum_{r=1}^{T} \operatorname{rel}(v, r)\right]$, where $S$ is the number of intended reference animals, and $\operatorname{rel}(v, r)$ refers to the relationship between validation animal $v$ and reference animal $r$. The average top 5 (rel5) and 10 (rel10) relationships were reported because they have been shown to have strong correlation to accuracy of genomic prediction (Daetwyler et al., 2013; Neves et al., 2014).

Prediction Accuracy. The estimate of reliability of GEBV $\left(\mathbf{R}_{\text {PEV }}^{2}\right)$ was calculated based on the diagonal of the coefficient matrix (prediction error variance approach) following VanRaden et al. (2009). The method blends EBV and accuracies of parent average information with accuracies of direct genomic values. Reliabilities computed as $\mathrm{R}_{\text {PEV }}^{2}$ are directly comparable to reliabilities of parent average $\left(\mathbf{R}_{\mathbf{P A}}^{2}\right)$, which was also computed from the diagonal of the coefficient matrix using pedigree and phenotype data at year 2014. Although, reliabilities computed as the squared correlation between GEBV and dEBV divided by the average reliability of validation animals have mostly been used in assessing the prediction accuracy $\left[r_{(\mathrm{dEBV}, \mathrm{GEBV})}^{2}=\operatorname{cor}^{2}(\mathrm{dEBV}, \mathrm{GEBV}) / r_{\mathrm{dEBV}}^{2}\right]$, due to the 
Table 2. Descriptive statistics of the number of animals $(\mathrm{N})$, estimated breeding values (EBV), reliabilities $\left(\mathrm{R}^{2}\right)$, and parent averages $(\mathrm{PA})$ and their respective SD (in parentheses) computed from pedigree and phenotype data

\begin{tabular}{|c|c|c|c|c|c|c|c|c|c|}
\hline Trait $^{1}$ & $\begin{array}{l}\text { Information } \\
\text { source }\end{array}$ & \multicolumn{3}{|c|}{ Reference population } & \multicolumn{5}{|c|}{ Validation population } \\
\hline$\overline{\mathrm{MY}}$ & $\begin{array}{l}\text { Bulls } \\
\text { Cows }\end{array}$ & $\begin{array}{r}281 \\
1,597\end{array}$ & $\begin{array}{c}597.0 \\
(374.0) \\
602.0 \\
(424.0)\end{array}$ & $\begin{array}{c}0.782 \\
(0.104) \\
0.590 \\
(0.071)\end{array}$ & 152 & $\begin{array}{c}1,031.0 \\
(288.0)\end{array}$ & $\begin{array}{c}0.443 \\
(0.093)\end{array}$ & $\begin{array}{c}1,042.0 \\
(285.2)\end{array}$ & $\begin{array}{c}0.39 \\
(0.04)\end{array}$ \\
\hline FY & $\begin{array}{l}\text { Bulls } \\
\text { Cows }\end{array}$ & $\begin{array}{r}274 \\
1,471\end{array}$ & $\begin{array}{c}25.4 \\
(19.8) \\
23.9 \\
(19.0)\end{array}$ & $\begin{array}{c}0.601 \\
(0.149) \\
0.445 \\
(0.094)\end{array}$ & 126 & $\begin{array}{c}48.7 \\
(19.4)\end{array}$ & $\begin{array}{c}0.330 \\
(0.047)\end{array}$ & $\begin{array}{c}49.0 \\
(19.3)\end{array}$ & $\begin{array}{c}0.31 \\
(0.04)\end{array}$ \\
\hline PY & $\begin{array}{l}\text { Bulls } \\
\text { Cows }\end{array}$ & $\begin{array}{r}264 \\
1,177\end{array}$ & $\begin{array}{c}13.8 \\
(14.7) \\
15.3 \\
(15.8)\end{array}$ & $\begin{array}{c}0.561 \\
(0.161) \\
0.436 \\
(0.114)\end{array}$ & 115 & $\begin{array}{c}28.5 \\
(10.0)\end{array}$ & $\begin{array}{c}0.320 \\
(0.045)\end{array}$ & $\begin{array}{c}28.6 \\
(10.0)\end{array}$ & $\begin{array}{c}0.30 \\
(0.04)\end{array}$ \\
\hline $\mathrm{AFC}$ & $\begin{array}{l}\text { Bulls } \\
\text { Cows }\end{array}$ & $\begin{array}{r}281 \\
1,582\end{array}$ & $\begin{array}{r}-117.5 \\
(73.5) \\
-89.0 \\
(64.9)\end{array}$ & $\begin{array}{c}0.733 \\
(0.108) \\
0.475 \\
(0.089)\end{array}$ & 151 & $\begin{array}{r}-197.4 \\
(64.3)\end{array}$ & $\begin{array}{c}0.421 \\
(0.099)\end{array}$ & $\begin{array}{r}-198.3 \\
(55.4)\end{array}$ & $\begin{array}{c}0.38 \\
(0.04)\end{array}$ \\
\hline
\end{tabular}

${ }^{1}$ Trait: milk (MY), protein (PY), and fat (FY) yield; age at first calving (AFC).

${ }^{2} \mathrm{PA}$ : parent average EBV computed from pedigree and phenotype data at year 2014.

${ }^{3} \mathrm{R}_{\mathrm{PA}}^{2}$ is the reliability of parent average.

structure of our data set and the relatively low number of reference and validation animals with unreliable dEBV (a proxy for true breeding value), this measure of prediction accuracy can results in highly inflated reliabilities with values exceeding 1 in most cases.

Scale of Genomic Predictions. In addition to reporting reliabilities, a weighted linear regression of dEBV of validation bulls on GEBV was fitted to estimate inflation or deflation of GEBV (regression coefficient; $\left.b_{1}\right)$

$$
\mathrm{dEBV}=b_{0}+b_{1} \hat{g}+e,
$$

where $\mathrm{dEBV}$ is the deregressed breeding value, $b_{0}$ is the intercept, $b_{1}$ is the regression coefficient, and $\hat{g}$ is the estimated genomic breeding values of the validation bulls. The residual term, $e$, was weighted with the reliability of dEBV of validation bulls.

\section{RESULTS}

\section{Reliability of Genomic Predictions}

Reliability Using Only Bulls in Reference Population. Reliability of genomic prediction using only bulls (TR1) in the reference population are presented in Figure 2. Reliability ranged from $\sim 0.46$ (FY and $\mathrm{PY})$ to 0.56 (MY). When averaged across all traits, $\mathrm{R}_{\mathrm{PEV}}^{2}$ were substantially higher $\left(\mathrm{R}_{\mathrm{PEV}}^{2}\right.$ of $\left.\mathrm{TR} 1=0.51\right)$ compared with reliabilities of parent averages $\left(\mathrm{R}_{\mathrm{PA}}^{2}=\right.$ 0.35 ; Table 3 ). The increase in $\mathrm{R}_{\mathrm{PEV}}^{2}$ was about 0.16 representing an increase of about $46 \%$.
Increasing Reference Population with Cows. When the bull reference population was increased by adding genotyped cows (TR2), reliabilities (averaged over all SNP panels and traits) were higher than using TR1 $\left(\mathrm{R}_{\mathrm{PEV}}^{2}\right.$ of TR1 $=0.51$ vs. $\mathrm{R}_{\mathrm{PEV}}^{2}$ and TR2 $=$ 0.57 ; Table 3, Figure 2). In comparison to $\mathrm{R}_{\mathrm{PA}}^{2}$, large increases were observed with TR2. The gain in $\mathrm{R}_{\mathrm{PEV}}^{2}$ when using TR2 compared with $\mathrm{R}_{\mathrm{PA}}^{2}$ was about $62 \%$ $\left(\mathrm{R}_{\mathrm{PA}}^{2}=0.39\right.$ vs. $\left.\mathrm{R}_{\mathrm{PEV}}^{2}=0.63\right)$ for MY, $73 \%\left(\mathrm{R}_{\mathrm{PA}}^{2}=\right.$ 0.31 vs. $\left.\mathrm{R}_{\mathrm{PEV}}^{2}=0.54\right)$ for $\mathrm{FY}, 55 \%\left(\mathrm{R}_{\mathrm{PA}}^{2}=0.30 \mathrm{vs}\right.$. $\left.\mathrm{R}_{\mathrm{PEV}}^{2}=0.52\right)$ for $\mathrm{PY}$, and $57 \%\left(\mathrm{R}_{\mathrm{PA}}^{2}=0.38\right.$ vs. $\mathrm{R}_{\mathrm{PEV}}^{2}$ $=0.60)$ for AFC averaged across all SNP panels. The addition of cow data to the bull reference data set, increased the total number of animals by about 5 folds.

Effect of Imputed Genotypes on Reliability. To mimic what might practically be undertaken to reduce cost of implementing of genomic selection, we assumed that reference animals were genotyped on Illumina HD and validation animals on SGGP-20Ki, 50K, and GGP$75 \mathrm{Ki}$ and imputed to the high-density panel. Imputation accuracies are reported in Table 4. Generally, imputation of young bulls were highly accurate (correlation $>0.96$ ), although some few individuals were poorly imputed (correlation <0.72). As expected, imputation accuracy [correlation (allelic correct rate)] was highest for GGP-75Ki [0.986 (0.997)], followed by 50K [0.974 (0.993)] and, finally, SGGP-20Ki [0.969 (0.993)].

Compared with using nonimputed genotypes, the average $\mathrm{R}_{\mathrm{PEV}}^{2}$ for imputed validation bulls was similar to results obtained when nonimputed bulls were used (Supplemental Table S1; https:/doi.org/10.3168/ jds.2016-11811). 
Comparing SNP Densities. With TR1, we found no clear increase in $\mathrm{R}_{\mathrm{PEV}}^{2}$ when marker density increased from 15,000 (SGGP-20Ki) to 496,606 (HD) markers (Figure 2). When using the TR2 reference population, a slight increase in $\mathrm{R}_{\mathrm{PEV}}^{2}$ was observed for the HD panel over other SNP panels for all traits, except for protein yield. The average increase in $\mathrm{R}_{\mathrm{PEV}}^{2}$ across all traits of the HD marker panel compared with SGGP-20Ki was about $0.02(3.3 \%)$ reliability points.

\section{Reference and Validation Animals' Relatedness and Effect on Reliability}

The average genomic relationship between reference and validation animals can be seen in Table 5. Average top 5 (rel5) or 10 (rel10) relationships between validation and reference animals was generally high, with values ranging from 0.32 to 0.44 (rel5) and 0.26 to 0.39 (rel10). Little to no difference in relatedness
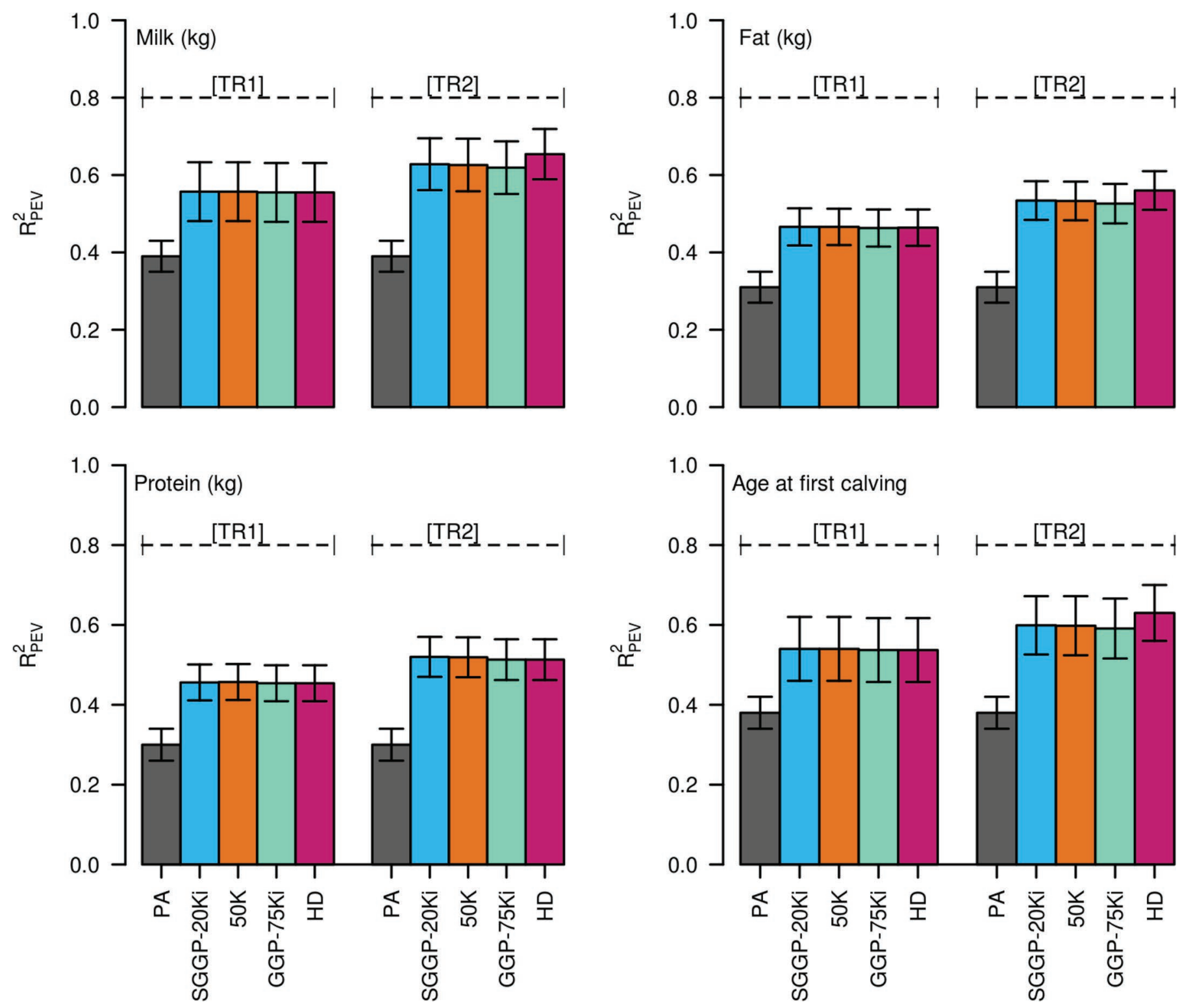

Figure 2. The average reliability $\left(\mathrm{R}_{\mathrm{PEV}}^{2}\right)$ using genomic BLUP model with only bulls (TR1) or bulls and cows (TR2) reference population. Errors bars represent the SD based on the computed reliabilities per animal. PA = parent average EBV computed from pedigree and phenotype data at year 2014; HD = Illumina BovineHD; 50K = Illumina BovineSNP50 (Illumina, San Diego, CA); SGGP-20Ki = GeneSeek SGGP IndicusLD; GGP-75Ki = GeneSeek GGP IndicusHD (Geneseek, Lincoln, NE). Color version available online. 
Table 3. Gains in reliability $\left(\mathrm{R}_{\mathrm{PEV}}^{2}\right)$ of genomic breeding values (GEBV) compared with parent averages $\left(\mathrm{R}_{\mathrm{PA}}^{2}\right)$, inflation or deflation ${ }^{1}$ of genomic predictions $\left(b_{1}\right)$ with bulls (TR1) or bulls and cows (TR2) in the reference population

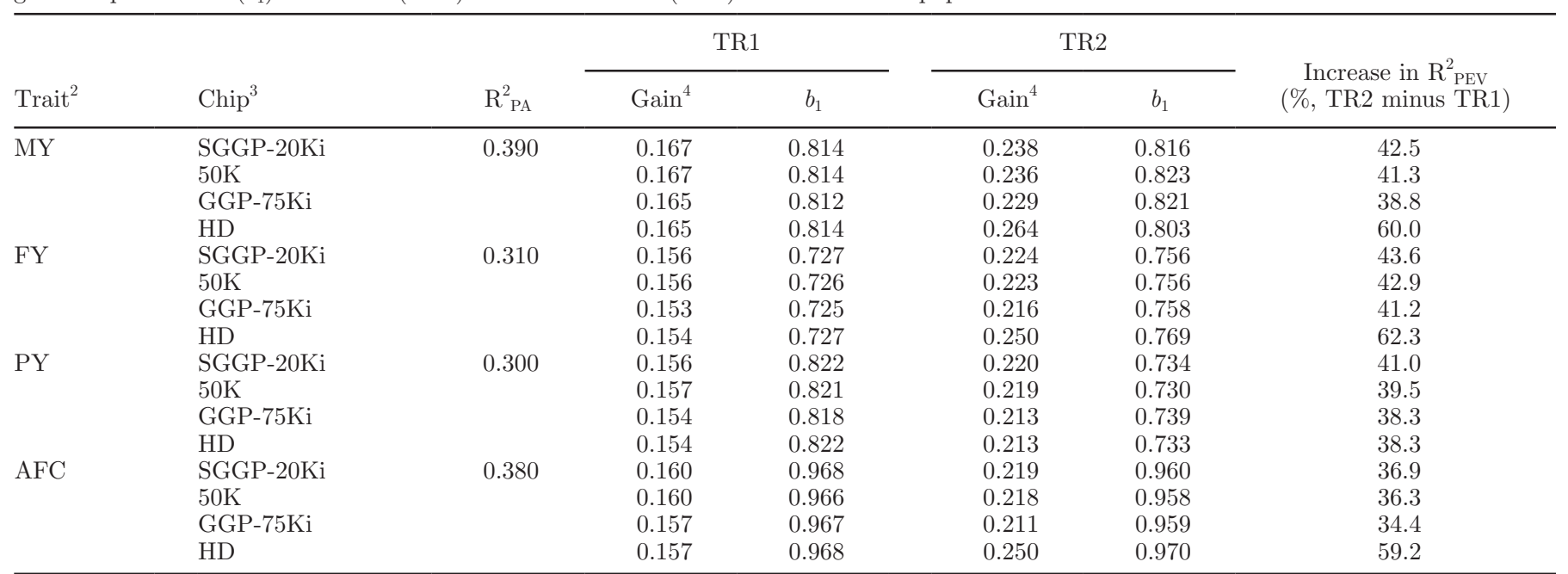

${ }^{1}$ Inflation or deflation of genomic predictions measured by the slope of the weighted regression of de-regressed EBV on GEBV.

${ }^{2}$ Trait: milk (MY), protein (PY) and fat (FY) yield; age at first calving (AFC).

${ }^{3}$ Chip: HD = Illumina BovineHD, 50K = Illumina BovineSNP50 (Illumina, San Diego, CA); SGGP-20Ki = GeneSeek SGGP IndicusLD, GGP$75 \mathrm{Ki}=$ GeneSeek GGP IndicusHD (Geneseek, Lincoln, NE).

${ }^{4}$ Gains: $\mathrm{R}_{\mathrm{PEV}}^{2}$ minus $\mathrm{R}_{\mathrm{PA}}^{2}$; the difference between $\mathrm{R}_{\mathrm{PEV}}^{2}$ and $\mathrm{R}_{\mathrm{PA}}^{2}$ measures the gain from using genomic information.

was observed among traits. The observed differences in average genomic relationships among traits were just due to the differing number of animals that constituted the reference and validation populations. The highest increases in relatedness were observed when the reference population was increased with cow data, with rel5 (rel10)] values ranging from $0.40(0.36)$ to $0.44(0.39)$.

We regressed $R_{\text {PEV }}^{2}$ on relatedness (rel5, rel10) to assess the effect of having relatives in the reference population. Averaging over all traits and marker panels, correlation between $\mathrm{R}_{\mathrm{PEV}}^{2}$ and rel5 was $\sim 0.45$ and the same for rel10 (Figure 3). The results of regressing $\mathrm{R}_{\text {PEV }}^{2}$ on relatedness suggested that when average top 5 relatedness increases by 0.1 (i.e., $0.5 / 5$; assuming that a sire of a selection candidate is added to the reference population), $\mathrm{R}_{\mathrm{PEV}}^{2}$ increased substantially by about 0.05 (regression coefficient was $\sim 0.5$ ).

\section{Scale of Genomic Predictions}

The slope $\left(b_{1}\right)$ of the weighted regression of dEBV on GEBV represented inflation or deflation of GEBV. The desired value is 1 , while inflation or deflation of GEBV means that $b_{1}$ is less or greater than 1 , respectively. The GEBV of MY, FY, and PY were inflated $\left(b_{1}\right.$ ranged from 0.73 to 0.81 ; Table 3); however, inflation of GEBV was small for age at first calving $(\sim 0.96)$.

\section{DISCUSSION}

The overall objective of our study was to investigate the benefits of using genomic information on accuracy of prediction for 4 traits, AFC, MY, FY, and PY, in Gyr (Bos indicus) dairy cattle of Brazil. Prediction accuracy and inflation or deflation of GEBV were studied using

Table 4. Summary of sample-specific imputation accuracy for young bulls (born after 2004) imputed from SGGP-20Ki, 50K, and GGP-75Ki to HD

\begin{tabular}{|c|c|c|c|c|}
\hline \multirow[b]{3}{*}{ Chip (LDP/HDP) } & \multicolumn{4}{|c|}{ Imputation accuracy } \\
\hline & \multicolumn{2}{|c|}{ Correlation } & \multicolumn{2}{|c|}{ Allelic correct rate } \\
\hline & Mean (SD) & Minimum & Mean (SD) & Minimum \\
\hline SGGP-20Ki/HD & $0.969(0.046)$ & 0.529 & $0.993(0.012)$ & 0.868 \\
\hline $50 \mathrm{~K} / \mathrm{HD}$ & $0.974(0.039)$ & 0.610 & $0.993(0.010)$ & 0.889 \\
\hline GGP-75Ki/HD & $0.986(0.024)$ & 0.711 & $0.997(0.005)$ & 0.925 \\
\hline
\end{tabular}


Table 5. Description of pedigree structure and average genomic relationship (rel5 and rel10) ${ }^{1}$ across training [bulls (TR1) or bulls and cows (TR2)] and validation data set

\begin{tabular}{|c|c|c|c|c|c|c|c|}
\hline \multirow{2}{*}{ Trait $^{2}$} & \multirow{2}{*}{$\begin{array}{l}\text { Total validation } \\
\text { animals (no.) }\end{array}$} & \multirow{2}{*}{$\begin{array}{l}\text { No. of validation } \\
\text { animals with sire in } \\
\text { reference (TR1) }\end{array}$} & \multirow{2}{*}{$\begin{array}{l}\text { No. of validation animals } \\
\text { with at least } 1 \text { parent } \\
\text { in reference (TR2) }\end{array}$} & \multicolumn{4}{|c|}{ Genomic relationship } \\
\hline & & & & \multicolumn{2}{|c|}{ rel5 } & \multicolumn{2}{|c|}{ rel10 } \\
\hline$\overline{\mathrm{MY}}$ & 152 & 143 & 146 & $\begin{array}{c}0.321 \\
(0.054)\end{array}$ & $\begin{array}{c}0.402 \\
(0.061)\end{array}$ & $\begin{array}{c}0.262 \\
(0.049)\end{array}$ & $\begin{array}{c}0.356 \\
(0.059)\end{array}$ \\
\hline FY & 126 & 122 & 125 & $\begin{array}{c}0.331 \\
(0.049)\end{array}$ & $\begin{array}{c}0.410 \\
(0.056)\end{array}$ & $\begin{array}{c}0.270 \\
(0.046)\end{array}$ & $\begin{array}{l}0.365 \\
(0.054)\end{array}$ \\
\hline $\mathrm{AFC}$ & 151 & 143 & 146 & $\begin{array}{c}0.322 \\
(0.054)\end{array}$ & $\begin{array}{c}0.402 \\
(0.062)\end{array}$ & $\begin{array}{c}0.262 \\
(0.049)\end{array}$ & $\begin{array}{l}0.356 \\
(0.059)\end{array}$ \\
\hline
\end{tabular}

${ }^{1}$ Genomic relationships: mean of the average top 5 (rel5) and top 10 (rel10) relationships with SD in parentheses.

${ }^{2}$ Trait: milk (MY), protein (PY), and fat (FY) yield; age at first calving (AFC).

GBLUP model and different marker panels (HD, 50K, GGP-75Ki, and SGGP-20Ki). Additionally, evaluating the effect of increasing the bull reference population with genotyped cow information was also studied.

\section{Reliability and Scale of Genomic Prediction}

We observed substantially higher reliabilities of genomic breeding values than of parent averages. The observed differences in $\mathrm{R}_{\mathrm{PEV}}^{2}$ of young bulls compared with $\mathrm{R}_{\mathrm{PA}}^{2}$ are similar to those reported for US Holstein (VanRaden et al., 2009), but higher than what was reported in Chinese Holstein (Ding et al., 2013). The strong relationship between reference and validation animals could have led to the high reliability for this population (Table 5). Furthermore, compared with the study of Ding et al. (2013), our reference population had many more animals with reliable EBV. To understand the gain in reliability in terms of the number of daughter records, $\mathrm{R}_{\mathrm{PEV}}^{2}$ were converted to the equivalent number of daughter information following standard selection index formulae. When using TR1, $\mathrm{R}_{\mathrm{PEV}}^{2}$ could be approximated to have phenotypic information on about 25,17, 15, and 14 daughters for MY, FY, PY, and AFC, respectively; the number of daughter information increased to $32,23,15$, and 18 with TR2 reference population.

As expected, $\mathrm{R}_{\mathrm{PEV}}^{2}$ of GEBV increased with increasing relatedness between validation and reference populations. The relationship between the reference and validation populations reported in our study was higher compared with report from other populations (Clark et al., 2012; Neves et al., 2014). The current validation scheme provided little information about reliabilities for individuals without relatives in the reference population. However, results from several other studies (Clark et al., 2012; Badke et al., 2014; Hozé et al., 2014; Neves et al., 2014) have shown that animals without parent or strong relationships in the reference populations would generally have lower $\mathrm{R}_{\mathrm{PEV}}^{2}$.

To reduce the cost of implementing genomic evaluation in breeding programs, selection candidates were assumed genotyped on 3 lower density panel (50K, SGGP-20Ki, and GGP-75Ki) and imputed to the HD. In our study, accuracy of imputation was high due to the strong relationship $(\sim 0.5)$ between imputed animals and reference population. As a result, $R_{\text {PEV were }}^{2}$ similar to what was obtained with the true or observed HD genotypes; however, several other studies (Mulder et al., 2012; Pimentel et al., 2015) have reported loss in reliability when using imputed genotypes on selection candidates.

Little to no changes in the scale of GEBV for validation bulls were observed when reference population included either bulls only or bulls and cows. The use of dEBV instead of yield deviation of cows might have reduced the problem. In addition, the cows used were not only elite cows but also a sample of the current cow population. The inflation of breeding values observed for FY, PY, and MY could be mitigated by incorporating polygenic effect through direct fitting of pedigree relationship or a combined genomic and pedigree relationship has been suggested (Dassonneville et al., 2012).

\section{Increasing Reference Population with Cow Data}

We observed an increase in $\mathrm{R}_{\mathrm{PEV}}^{2}$ when reference population was increased from an average of 273 (bulls only) to 1,455 (bulls and cows). In a simulation study, Thomasen et al. (2014) reported increase in accuracy for selection candidate when cow information were added to a relatively small reference population of bulls. Ding et al. (2013) also showed that, in the absence of reliable 
sires that can constitute reference populations for Chinese Holstein, relatively large cow reference population gave more reliable GEBV compared with parent average reliabilities. One reason for the increase in reliability with TR2 in this population was the increase in sample size from the addition of related cow data, which resulted in an increase in relatedness between validation and reference animals (Table 5 ). In addition, increasing the reference population leads to more accurate estimation of model parameters and reduction of standard error of prediction. However, the substantial increase in reliability with the addition of cow data has not been observed in other cattle population (US Holstein; Cooper et al., 2015), but this could be due to the large number of sires already genotyped and used as reference animals for those populations. Additionally, an important con-
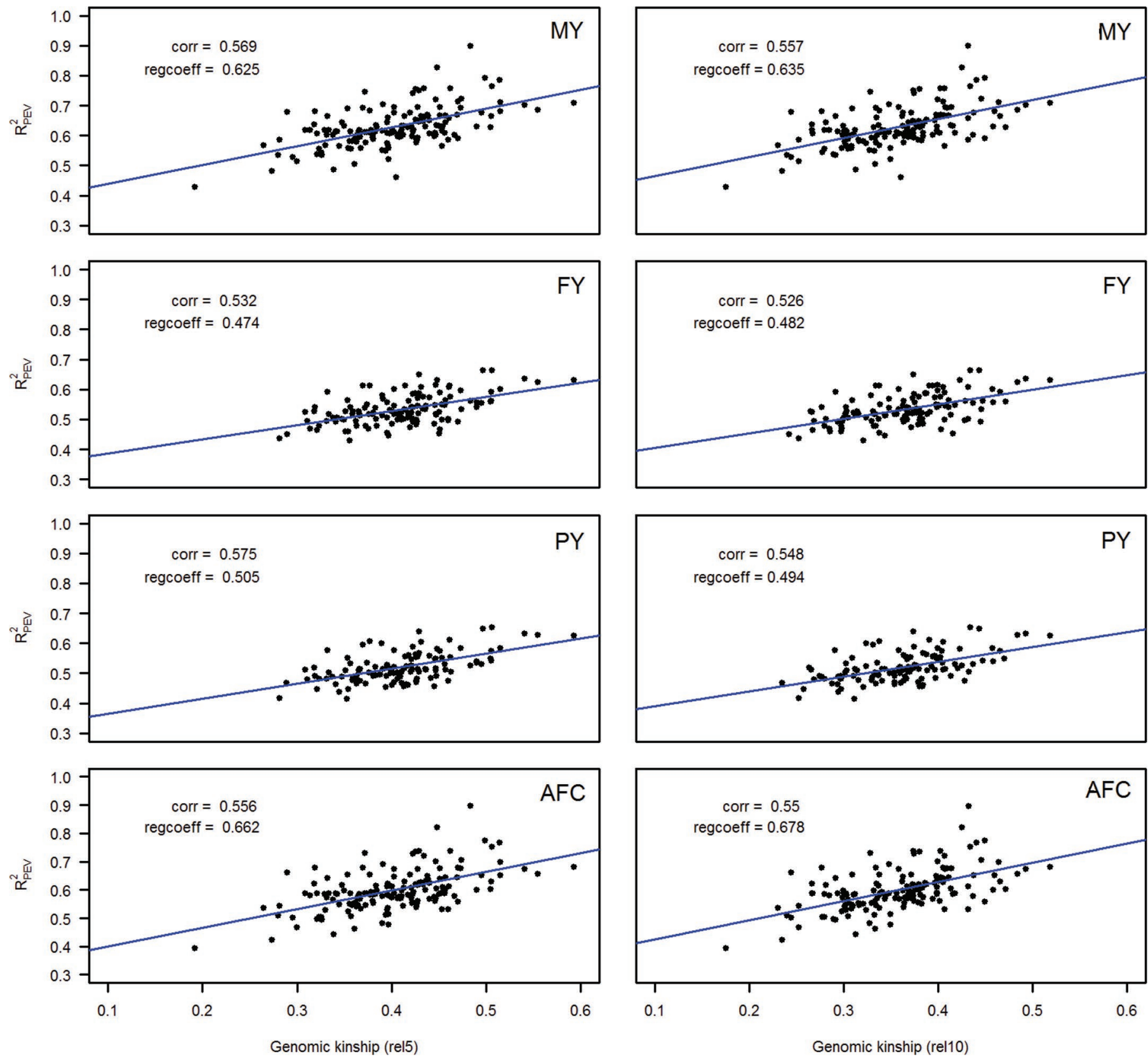

Figure 3. Plot of reliability against genomic relationship [mean of the average top 5 (rel5) and top 10 (rel10) relationships] for milk (MY), fat $(\mathrm{FY})$, and protein (PY) yield and age at first calving (AFC). Corr is the correlation between genomic relationship and gains in reliability $\left(\mathrm{R}_{\mathrm{PEV}}^{2}\right)$; regcoeff is the regression coefficient obtained from the regression of $\mathrm{R}_{\mathrm{PEV}}^{2}$ on genomic relatedness. Solid line is the regression line of genomic relationship on reliability. Color version available online. 
sideration when using cow information is the avoidance of double counting, as dEBV of genotyped sires might contain information from the added cows. Suggested approaches to deal with this problem would require the elimination of genotyped cows that had genotyped sires in the reference population (Calus et al. 2013). However, recent deregression methods suggested by Calus et al. (2016) would allow for removal of information of genotyped cows from genotyped sires EBV, allowing for both animals to remain in the reference population and mitigating against double counting.

\section{Increasing Marker Density}

On average, little to no gain in $\mathrm{R}_{\text {PEV }}^{2}$ was observed with the HD marker data. Several other studies have reported slightly higher reliabilities when using the $777 \mathrm{~K}$ genotype data compared with the $50 \mathrm{~K}$ (Erbe et al., 2012; Hozé et al., 2014). In our study, a slight increase in $\mathrm{R}_{\mathrm{PEV}}^{2}$ was observed with the $\mathrm{HD}$ data when using TR2 (bull and cow) reference population for almost all traits. However, the increase in $\mathrm{R}_{\mathrm{PEV}}^{2}$ with TR2 when using the HD marker panel may be an artifact. Adding a huge number of imputed cow genotypes to the reference population may have led to the inflation. Badke et al. (2014) reported higher accuracies $\left(\sqrt{R_{\mathrm{PEV}}^{2}}\right)$ when imputed genotypes with high errors (correlation between imputed and true genotypes was $\sim 0.88$ ) were added to the reference population. Those authors also observed that when imputation accuracies were $>0.95$, accuracies were not inflated. Erroneous imputations can lead to artificial relatedness (Badke et al., 2014; Pimentel et al., 2015) between animals and can lead to increases in reliability for genetically inferior selection candidates and reference animals. This is because, when imputation software packages cannot infer haplotypes of certain animals at a particular genomic region, often the most frequent haplotype is assigned.

Interestingly, even for production traits (milk, fat, and protein), increasing marker density did not increase reliability of GEBV except for the artifact described above. These traits (MY, FY, and PY) have been shown to be influenced by QTL, with a large effect in most Bos taurus population (Bolormaa et al., 2010; Cole et al., 2011; Ding et al., 2013; Minozzi et al., 2013; Raven et al., 2014). However, for Bos indicus dairy cattle populations, a lack of knowledge exists as to which QTL (as well as their allele substitution effect) have an effect on the traits of economic importance. For example, most of the markers that have been reported as significant for milk production traits (MY, FY, and PY) and are located in the region of DGAT1 on chro- mosome 14 (Grisart et al., 2004) were present on the HD panel for our study. However, our analysis did not show evidence of QTL on chromosome (Supplemental Figure S1; https://doi.org/10.3168/jds.2016-11811). This may be due to limited data size (power to detect QTL) combined with the low minor allele frequency of markers in that region. Recently, Rosse et al. (2014) reported that the key marker of DGAT1 is fixed in Guzerat (dual-purpose Bos indicus) cattle of Brazil. Researchers in our group are undertaking comprehensive QTL mapping and initial results suggest different genomic regions might have a large effect on milk production traits in Gyr (data not shown).

\section{CONCLUSIONS}

The results from this study demonstrate the benefits of adding genomic information for genetic evaluation of the Gyr population. Reliability of genomic breeding values for AFC, MY, Fy, and PY was moderate to high, although the number of animals in the reference population was limited $(\mathrm{n}=\sim 273$ bulls and $\sim 1,455$ bulls and cows). Reliabilities $\left(\mathrm{R}_{\mathrm{PEV}}^{2}\right)$ were substantially higher (an increase of 0.09 to 0.27 ) compared with reliability of parent averages $\left(\mathrm{R}_{\mathrm{PEV}}^{2}=0.35\right)$. Addition of genotyped cows into the reference population that caused a 5 -fold increase in the number of reference animals resulted in a strong increase in reliability. However, addition of imputed animals into the reference population could cause an artificial increase in $\mathrm{R}_{\mathrm{PEV}}^{2}$. Reliability of GEBV was on average similar for all marker panels (HD, 50K, GGP-75Ki, and SGGP-20Ki) and thus the cheapest marker panel could be adopted by breeding organizations to minimize cost of implementing genomic selection in the Gyr population.

\section{ACKNOWLEDGMENTS}

Marcos V. G. B. Silva was supported by the Embrapa (Brazil) Sistema Embrapa de Gestão 02.09.07.008.00.00 "Genomic Selection in Dairy Cattle in Brazil," Consehlo Nacional de Desenvolvimento Científico e Tecnológico Pesquisador Visitante Especial 407246/2013-4 "Genomic Selection in Dairy Gyr and Girolando Breeds," and Fundação de Amparo à Pesquisa de Minas Gerais Câmara de Veterinária e Zootecnia Programa Pesquisador Mineiro 00395/14 "Genomic Selection in Brazilian Dairy Breeds" appropriated projects.

\section{REFERENCES}

Amer, P. R., and G. Banos. 2010. Implications of avoiding overlap between training and testing data sets when evaluating genomic predictions of genetic merit. J. Dairy Sci. 93:3320-3330. https:// doi.org/10.3168/jds.2009-2845. 
Badke, Y. M., R. O. Bates, C. W. Ernst, J. Fix, and J. P. Steibel. 2014. Accuracy of estimation of genomic breeding values in pigs using low-density genotypes and imputation. G3 (Bethesda) 4:623-631. https://doi.org/10.1534/g3.114.010504.

Boison, S. A., D. J. a. Santos, H. T. Utsunomiya, R. Carvalheiro, H. H. R. Neves, M. P. O'Brien, J. F. Garcia, J. Sölkner, and M. V. G. B. da Silva. 2015. Strategies for single nucleotide polymorphism genotyping to enhance genotype imputation in Gyr (Bos indicus) dairy cattle: Comparison of commercially available single nucleotide polymorphism chips. J. Dairy Sci. 98:4969-4989. https://doi. org/10.3168/jds.2014-9213.

Bolormaa, S., J. E. Pryce, B. J. Hayes, and M. E. Goddard. 2010. Multivariate analysis of a genome-wide association study in dairy cattle. J. Dairy Sci. 93:3818-3833. https://doi.org/10.3168/ jds.2009-2980.

Brøndum, R. F., E. Rius-Vilarrasa, I. Strandén, G. Su, B. Guldbrandtsen, W. F. Fikse, and M. S. Lund. 2011. Reliabilities of genomic prediction using combined reference data of the Nordic Red dairy cattle populations. J. Dairy Sci. 94:4700-4707. https://doi. org/10.3168/jds.2010-3765.

Calus, M. P. L., Y. de Haas, and R. F. Veerkamp. 2013. Combining cow and bull reference populations to increase accuracy of genomic prediction and genome-wide association studies. J. Dairy Sci. 96:6703-6715. https://doi.org/10.3168/jds.2012-6013.

Calus, M. P. L., J. Vandenplas, J. ten Napel, and R. F. Veerkamp. 2016. Validation of simultaneous deregression of cow and bull breeding values and derivation of appropriate weights. J. Dairy Sci. 99:6403-6419. https://doi.org/10.3168/jds.2016-11028.

Clark, S. A., J. M. Hickey, H. D. Daetwyler, and J. H. J. van der Werf. 2012. The importance of information on relatives for the prediction of genomic breeding values and the implications for the makeup of reference data sets in livestock breeding schemes. Genet. Sel. Evol. 44:4. https://doi.org/10.1186/1297-9686-44-4.

Cole, J. B., G. R. Wiggans, L. Ma, T. S. Sonstegard, T. J. Lawlor, B. A. Crooker, C. P. Van Tassell, J. Yang, S. Wang, L. K. Matukumalli, and Y. Da. 2011. Genome-wide association analysis of thirty one production, health, reproduction and body conformation traits in contemporary U.S. Holstein cows. BMC Genomics 12:408. https://doi.org/10.1186/1471-2164-12-408.

Cooper, T. A., G. R. Wiggans, and P. M. Vanraden. 2015. Short communication: Analysis of genomic predictor population for Holstein dairy cattle in the United States -Effects of sex and age. J. Dairy Sci. 98:2785-2788. https://doi.org/10.3168/jds.2014-8894.

Daetwyler, H. D., M. P. L. Calus, R. Pong-Wong, G. de Los Campos, and J. M. Hickey. 2013. Genomic prediction in animals and plants: Simulation of data, validation, reporting, and benchmarking. Genetics 193:347-365. https://doi.org/10.1534/genetics.112.147983.

Dassonneville, R., A. Baur, S. Fritz, D. Boichard, and V. Ducrocq. 2012. Inclusion of cow records in genomic evaluations and impact on bias due to preferential treatment. Genet. Sel. Evol. 44:40 https://doi.org/10.1186/1297-9686-44-40.

Ding, X., Z. Zhang, X. Li, S. Wang, X. Wu, D. Sun, Y. Yu, J. Liu, Y. Wang, Y. Zhang, S. Zhang, and Q. Zhang. 2013. Accuracy of genomic prediction for milk production traits in the Chinese Holstein population using a reference population consisting of cows. J. Dairy Sci. 96:5315-5323. https://doi.org/10.3168/jds.2012-6194.

Erbe, M., B. J. Hayes, L. K. Matukumalli, S. Goswami, P. J. Bowman, C. M. Reich, B. A. Mason, and M. E. Goddard. 2012. Improving accuracy of genomic predictions within and between dairy cattle breeds with imputed high-density single nucleotide polymorphism panels. J. Dairy Sci. 95:4114-4129. https://doi.org/10.3168/ jds.2011-5019.

Garrick, D. J., J. F. Taylor, and R. L. Fernando. 2009. Deregressing estimated breeding values and weighting information for genomic regression analyses. Genet. Sel. Evol. 41:55 https://doi. org $/ 10.1186 / 1297-9686-41-55$.

Grisart, B., F. Farnir, L. Karim, N. Cambisano, J.-J. Kim, A. Kvasz, M. Mni, P. Simon, J.-M. Frère, W. Coppieters, and M. Georges. 2004. Genetic and functional confirmation of the causality of the DGAT1 K232A quantitative trait nucleotide in affecting milk yield and composition. Proc. Natl. Acad. Sci. USA 101:2398-2403. https://doi.org/10.1073/pnas.0308518100.

Habier, D., R. L. Fernando, K. Kizilkaya, and D. J. Garrick. 2011. Extension of the bayesian alphabet for genomic selection. BMC Bioinformatics 12:186. https://doi.org/10.1186/1471-2105-12-186.

Hayes, B. J., P. J. Bowman, A. C. Chamberlain, K. Verbyla, and M. E. Goddard. 2009. Accuracy of genomic breeding values in multibreed dairy cattle populations. Genet. Sel. Evol. 41:51. https:// doi.org/10.1186/1297-9686-41-51.

Hozé, C., S. Fritz, F. Phocas, D. Boichard, V. Ducrocq, and P. Croiseau. 2014. Efficiency of multi-breed genomic selection for dairy cattle breeds with different sizes of reference population. J. Dairy Sci. 97:3918-3929. https://doi.org/10.3168/jds.2013-7761.

Hutchison, J. L., J. B. Cole, and D. M. Bickhart. 2014. Short communication: Use of young bulls in the United States. J. Dairy Sci. 97:3213-3220. https://doi.org/10.3168/jds.2013-7525.

Legarra, A., I. Aguilar, and I. Misztal. 2009. A relationship matrix including full pedigree and genomic information. J. Dairy Sci. 92:4656-4663. https://doi.org/10.3168/jds.2009-2061.

Lourenco, D. A. L., I. Misztal, S. Tsuruta, I. Aguilar, E. Ezra, M. Ron, A. Shirak, and J. I. Weller. 2014. Methods for genomic evaluation of a relatively small genotyped dairy population and effect of genotyped cow information in multiparity analyses. J. Dairy Sci. 97:1742-1752. https://doi.org/10.3168/jds.2013-6916.

Luan, T., J. A. Woolliams, S. Lien, M. Kent, M. Svendsen, and T. H. E. Meuwissen. 2009. The accuracy of Genomic Selection in Norwegian red cattle assessed by cross-validation. Genetics 183:11191126. https://doi.org/10.1534/genetics.109.107391.

Meuwissen, T. H., B. J. Hayes, and M. E. Goddard. 2001. Prediction of total genetic value using genome-wide dense marker maps. Genetics 157:1819-1829.

Minozzi, G., E. L. Nicolazzi, A. Stella, S. Biffani, R. Negrini, B. Lazzari, P. Ajmone-Marsan, and J. L. Williams. 2013. Genome wide analysis of fertility and production traits in Italian Holstein cattle. PLoS One 8:e80219. https://doi.org/10.1371/journal.pone.0080219.

Mulder, H. A., M. P. L. Calus, T. Druet, and C. Schrooten. 2012. Imputation of genotypes with low-density chips and its effect on reliability of direct genomic values in Dutch Holstein cattle. J. Dairy Sci. 95:876-889. https://doi.org/10.3168/jds.2011-4490.

Mulder, H. A., T. H. E. Meuwissen, M. P. L. Calus, and R. F. Veerkamp. 2010. The effect of missing marker genotypes on the accuracy of gene-assisted breeding value estimation: a comparison of methods. Animal 4:9. https://doi.org/10.1017/S1751731109990838.

Neves, H. H., R. Carvalheiro, A. M. O. Brien, Y. T. Utsunomiya, A. S. do Carmo, F. S. Schenkel, J. Sölkner, J. C. McEwan, C. P. Van Tassell, J. B. Cole, M. V. da Silva, S. A. Queiroz, T. S. Sonstegard, and J. F. Garcia. 2014. Accuracy of genomic predictions in Bos indicus (Nellore) cattle. Genet. Sel. Evol. 46:17. https://doi. org/10.1186/1297-9686-46-17.

Olson, K. M., P. M. Vanraden, M. E. Tooker, and T. A. Cooper. 2011. Differences among methods to validate genomic evaluations for dairy cattle. J. Dairy Sci. 94:2613-2620. https://doi.org/10.3168/ jds.2010-3877.

Pimentel, E. C. G., C. Edel, R. Emmerling, and K.-U. Götz. 2015. How imputation errors bias genomic predictions. J. Dairy Sci. 98:4131-4138. https://doi.org/10.3168/jds.2014-9170.

Purcell, S., B. Neale, K. Todd-Brown, L. Thomas, M. A. R. Ferreira, D. Bender, J. Maller, P. Sklar, P. I. W. de Bakker, M. J. Daly, and P. C. Sham. 2007. PLINK: a tool set for whole-genome association and population-based linkage analyses. Am. J. Hum. Genet. 81:559-575. https://doi.org/10.1086/519795.

Raven, L.-A., B. G. Cocks, and B. J. Hayes. 2014. Multibreed genome wide association can improve precision of mapping causative variants underlying milk production in dairy cattle. BMC Genomics 15:62. https://doi.org/10.1186/1471-2164-15-62.

Rosse, I. C., R. D. S. Steinberg, R. S. Coimbra, M. G. C. D. Peixoto, R. S. Verneque, M. A. Machado, C. G. Fonseca, and M. R. S. Carvalho. 2014. Novel SNPs and INDEL polymorphisms in the $3^{\prime}$ UTR of DGAT1 gene: in silico analyses and a possible association. Mol. Biol. Rep. 41:4555-4563. https://doi.org/10.1007/ s11033-014-3326-z. 
Santana, M. L., R. J. Pereira, B. Bignardi, L. El Faro, H. Tonhati, and L. G. Albuquerque. 2014. History, structure, and genetic diversity of Brazilian Gir cattle. Livest. Sci. 163:26-33. https://doi. org/10.1016/j.livsci.2014.02.007.

Sargolzaei, M., J. P. Chesnais, and F. S. Schenkel. 2014. A new approach for efficient genotype imputation using information from relatives. BMC Genomics 15:478. https://doi.org/10.1186/14712164-15-478.

Sargolzaei, M., F. S. Schenkel, and P. M. VanRaden. 2011. gebv: Genomic breeding value estimator for livestock. Page 1-7 in Technical Report to the Dairy Cattle Breeding and Genetics Committee. University of Guelph, Guelph, Canada.

Schaeffer, L. R. 2006. Strategy for applying genome-wide selection in dairy cattle. J. Anim. Breed. Genet. 123:218-223. https://doi. org/10.1111/j.1439-0388.2006.00595.x.

Su, G., B. Guldbrandtsen, V. R. Gregersen, and M. S. Lund. 2010. Preliminary investigation on reliability of genomic estimated breeding values in the Danish Holstein population. J. Dairy Sci. 93:1175-1183. https://doi.org/10.3168/jds.2009-2192.

Thomasen, J. R., A. C. Sørensen, M. S. Lund, and B. Guldbrandtsen. 2014. Adding cows to the reference population makes a small dairy population competitive. J. Dairy Sci. 97:5822-5832. https://doi org/10.3168/jds.2014-7906.

VanRaden, P. M. 2008. Efficient methods to compute genomic predictions. J. Dairy Sci. 91:4414-4423. https://doi.org/10.3168/ jds.2007-0980

VanRaden, P. M., C. P. Van Tassell, G. R. Wiggans, T. S. Sonstegard, R. D. Schnabel, J. F. Taylor, and F. S. Schenkel. 2009. Invited review: reliability of genomic predictions for North American Holstein bulls. J. Dairy Sci. 92:16-24. https://doi.org/10.3168/ jds.2008-1514

Wiggans, G. R., T. A. Cooper, P. M. Vanraden, and J. B. Cole. 2011. Technical note: Adjustment of traditional cow evaluations to improve accuracy of genomic predictions. J. Dairy Sci. 94:6188-6193. https://doi.org/10.3168/jds.2011-4481.

Wiggans, G. R., G. Su, T. A. Cooper, U. S. Nielsen, G. P. Aamand, B. Guldbrandtsen, M. S. Lund, and P. M. VanRaden. 2015. Short communication: Improving accuracy of Jersey genomic evaluations in the United States and Denmark by sharing reference population bulls. J. Dairy Sci. 98:3508-3513. https://doi.org/10.3168/ jds.2014-8874. 